\title{
STUDY TO DETERMINE OVERALL EXPERIENCE OF WOMEN UNDERGOING REGIONAL ANAESTHESIA FOR CAESAREAN SECTION
}

\author{
Pratibha Savant ${ }^{1}$, Ketaki Patwardhan², Vijay Patil ${ }^{3}$
}

1 Professor and HOD, Department of Anaesthesia, Rajiv Gandhi Medical College and Chatrapati Shivaji Maharaj Hospital, Kalwa, Thane, Mumbai, Maharashtra, India.

${ }^{2}$ Associate Professor, Department of Anaesthesia, Rajiv Gandhi Medical College and Chatrapati Shivaji Maharaj Hospital, Kalwa, Thane, Mumbai, Maharashtra, India.

${ }^{3}$ Associate Professor, Department of Anaesthesia, Rajiv Gandhi Medical College and Chatrapati Shivaji Maharaj Hospital, Kalwa, Thane, Mumbai, Maharashtra, India.

\begin{abstract}
BACKGROUND
ABSTRACT

The choice of anaesthesia for caesarean section depends on many factors including the indication for the caesarean section, whether the procedure is emergency or elective, NBM status of the patient, preoperative condition of the patient, any preoperative disease and the condition of the foetus. Even though as anaesthetists, we would prefer spinal anaesthesia as the anaesthesia of choice for caesarean section, we wanted to know the perception of women who have undergone spinal anaesthesia for caesarean section about the overall experience of the same.
\end{abstract}

Aim- To determine the overall experience of women undergoing regional anaesthesia for caesarean section.

\section{MATERIALS AND METHODS}

We conducted a cross-sectional study via a questionnaire on an online social media platform in a group, which consisted exclusively of mothers in the city of Mumbai. The questionnaire included basic questions about demographics of patients, any preexisting medical conditions complicating the pregnancy, the total number of children, number of caesarean surgeries they underwent, the type of anaesthesia received, the position and comfort during spinal anaesthesia, any apprehension felt during or after anaesthesia, awareness about surroundings, the pain relief post-surgery, any headache or backache after surgery, the overall experience of anaesthesia and the likelihood of them opting for spinal anaesthesia if need arises in future. The answers were computed by statistical analysis and the results were analysed.

\section{RESULTS}

In our study, 52\% did not feel apprehensive during induction of anaesthesia suggesting almost equal number of patients felt apprehensive during the same. The sitting position for spinal anaesthesia was found to be significantly comfortable. This result was surprising, because in lateral general position is perceived to be more comfortable than the sitting position while receiving spinal anaesthesia. In our study, 238 i.e. 72\% patients were pain free immediately after surgery. In our study, 32.92\% females had headache postoperatively. 180 out of 327 , i.e. almost $55 \%$ patients had experienced backache after the surgery. The same number of patients, 180 i.e. 55\% have persistent backache even years after the surgery. When we compared incidence of backache in patients receiving different types of anaesthesia, there was no statistically significant difference in the incidence of backache in those receiving spinal, general or epidural anaesthesia. Of the 327 patients in our study, almost $60 \%$ patients felt they would opt for spinal anaesthesia if required in future. In spite of all the apprehensions and prejudices, in our study $84.09 \%$ women found the overall experience of anaesthesia for caesarean surgery to be satisfactory.

\section{CONCLUSION}

In conclusion, this study shows that in spite of the advantages of neuraxial blockade for caesarean surgery a number of factors can decide the comfort of patient during the surgery including whether anaesthetist spoke to the patient prior to surgery, the apprehension felt while receiving anaesthesia, the position given or whether baby was shown immediately after birth. Backache is very common in these patients, but most of the times it becomes persistent due to factors like physiological changes of pregnancy and postpartum period. Irrespective of its aetiology and pathogenesis, the postpartum backache is attributed to spinal anaesthesia or epidural anaesthesia received during caesarean surgery.

\section{KEY WORDS}

Caesarean Section, Spinal Anaesthesia, Maternal Satisfaction.

HOW TO CITE THIS ARTICLE: Savant P, Patwardhan K, Patil V. Study to determine overall experience of women undergoing regional anaesthesia for caesarean section. J. Evolution Med. Dent. Sci. 2018;7(41):4403-4408, DOI: 10.14260/jemds/2018/983

'Financial or Other Competing Interest': None.

Submission 03-08-2018, Peer Review 21-09-2018,

Acceptance 27-09-2018, Published 08-10-2018.

Corresponding Author:

Dr. Ketaki Patwardhan,

Flat No. 1C, Angle Apartment, Cosmos Springs 2, Ovala,

Ghodbynder Road, Thane West, Mumbai, Maharashtra, India.

E-mail: ketaki_p18@yahoo.co.in

DOI: $10.14260 /$ jemds $/ 2018 / 983$

\section{BACKGROUND}

The choice of anaesthesia for caesarean surgery depends on many factors including the indication for the caesarean, whether the procedure is emergency or elective, NBM status of the patient, preoperative condition of the patient, any preoperative disease and the condition of the foetus. Spinal (subarachnoid) anaesthesia offers many advantages for caesarean delivery. It has a very rapid onset and provides a dense neural block. Because of the small doses used, there is little risk of local anaesthetic toxicity and minimal transfer of 
drug to the foetus. In addition, failures (including incomplete or patchy blocks) are very infrequent with spinal anaesthesia. Disadvantages of this technique include the finite duration of anaesthesia and a higher incidence of hypotension. Recently, regional anaesthesia has gained worldwide acceptance and its physiological effects provide a better outcome for caesarean section, moreover, general anaesthesia is associated with significantly high maternal morbidity and mortality. ${ }^{1}$ However, patients generally attribute chronic backache to previous spinal anaesthesia for caesarean surgery. Infact up to $75 \%$ of women who suffer from pregnancy-related back pain may continue to have pain after giving birth. While the majority of cases resolve within 6 months postpartum, 40\% may continue to experience pain

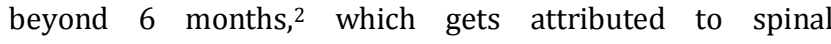
anaesthesia received during caesarean section.

Even though as anaesthetist, we would prefer spinal anaesthesia as the anaesthesia of choice for caesarean section, we wanted to know the perception of women who have undergone spinal anaesthesia for caesarean section about the overall experience of the same.

\section{MATERIALS AND METHODS}

We conducted a cross-sectional study via a questionnaire on an online social media platform in a group, which consisted exclusively of mothers in the city of Mumbai. Of the one lakh members, 328 participated in the study. The questionnaire was anonymous and willingness to answer it voluntarily was taken as implied consent. Of the 328 participants, one was excluded due to incomplete filling of questionnaire. The sample size estimation was also done at conveniences.

\section{Sampling Technique}

Convenient sampling method.

The age group of females taking part in the study was between 18 and 45. The questionnaire included basic questions about demographics of patients, any pre-existing medical conditions complicating the pregnancy, the total number of children, number of caesarean surgeries they underwent, the type of anaesthesia received, the position and comfort during spinal anaesthesia, any apprehension felt during or after anaesthesia, awareness about surroundings, the pain relief post-surgery, any headache or backache after surgery, the overall experience of anaesthesia and the likelihood of them opting for spinal anaesthesia if need arises in future. The answers were computed by statistical analysis and results were analysed. The data was represented as percentage distribution and Chi-square test was used for test of significance. Epi Info 7 software was used for analysis.

\section{RESULTS}

Following are the observations obtained from our study-

1. Demographics- Of the 327 females, there were only 3 below the age of 20 years and only 2 above the age of 40 . Maximum were in the age group of 26 to 30 years.

Pre-existing co-morbidities, i.e. Pregnancy-induced hypertension, Diabetes Mellitus or Anaemia were present in 203 patients. Only one patient amongst the 327 had all the three co-morbidities.
2. Whether the anaesthetist was introduced to the patient before caesarean surgery.

\begin{tabular}{|c|c|}
\hline & Introduction \\
\hline No & $120(36.69 \%)$ \\
\hline Yes & $207(63.31 \%)$ \\
\hline (blank) & $\mathbf{3 2 7}$ \\
\hline Total & \\
\hline
\end{tabular}

3. Type of anaesthesia administered.

\begin{tabular}{|c|c|c|c|c|c|}
\hline $\begin{array}{c}\text { Anaesthesia Type/ } \\
\text { LSCS }\end{array}$ & $\mathbf{0}$ & $\mathbf{1}$ & $\mathbf{2}$ & $\mathbf{3}$ & Total \\
\hline General Anaesthesia & & 16 & 7 & 2 & $25(7.65 \%)$ \\
\hline Spinal Anaesthesia & 2 & 168 & 92 & 2 & $264(80.73 \%)$ \\
\hline Epidural Anaesthesia & & 14 & 3 & & $17(5.19 \%)$ \\
\hline Cannot recall & & 14 & 7 & & $21(6.43 \%)$ \\
\hline Total & $\mathbf{2}$ & $\mathbf{2 1 2}$ & $\mathbf{1 0 9}$ & $\mathbf{4}$ & $\mathbf{3 2 7}$ \\
\hline
\end{tabular}

267 of 327 , i.e. $81 \%$ had caesarean surgery under spinal anaesthesia.

4. Whether patient felt apprehensive during anaesthesia induction.

\begin{tabular}{|c|c|c|c|c|c|}
\hline $\begin{array}{c}\text { Apprehension/ } \\
\text { LSCS }\end{array}$ & $\mathbf{0}$ & $\mathbf{1}$ & $\mathbf{2}$ & $\mathbf{3}$ & Total \\
\hline No & 1 & 119 & 50 & 3 & $173(52.90 \%)$ \\
\hline Yes & 1 & 93 & 59 & 1 & $154(47.10 \%)$ \\
\hline Total & $\mathbf{2}$ & $\mathbf{2 1 2}$ & $\mathbf{1 0 9}$ & $\mathbf{4}$ & $\mathbf{3 2 7}$ \\
\hline
\end{tabular}

$52 \%$ did not feel apprehensive during induction of anaesthesia, suggesting almost equal number of patients felt apprehensive during the same.

5. Position given for administration of spinal anaesthesia.

\begin{tabular}{|c|c|}
\hline & Position Spinal \\
\hline Lateral & $52(15.90 \%)$ \\
\hline NA & $25(7.65 \%)$ \\
\hline Sitting & $250(76.45 \%)$ \\
\hline Total & $\mathbf{3 2 7}$ \\
\hline
\end{tabular}

This suggests that majority (76\%) of patients receiving spinal anaesthesia were given subarachnoid block in the sitting position.

\section{Position and Comfort.}

\begin{tabular}{|c|c|c|c|}
\hline Comfort & No & Yes & Total \\
\hline Lateral & $24(35.29 \%)$ & $28(12.33 \%)$ & $52(17.62 \%)$ \\
\hline Sitting & $44(64.71 \%)$ & $199(87.67 \%)$ & $243(82.38 \%)$ \\
\hline Total & $\mathbf{6 8}$ & $\mathbf{2 2 7}$ & $\mathbf{2 9 5}$ \\
\hline
\end{tabular}

Sitting position was significantly more comfortable$\mathrm{X}^{2}=18.996, \mathrm{p}=0.00001$ (highly significant).

7. Whether patient was comfortable during anaesthesia.

\begin{tabular}{|c|c|}
\hline & Position Comfort \\
\hline NA & $28(8.56 \%)$ \\
\hline No & $70(21.40 \%)$ \\
\hline Yes & $229(70.04 \%)$ \\
\hline Total & $\mathbf{3 2 7}$ \\
\hline
\end{tabular}


$70 \%$ patients were comfortable during induction of spinal anaesthesia.

8. Pain relief after surgery.

\begin{tabular}{|c|c|}
\hline & Pain Relief after Surgery \\
\hline No & $89(27.21 \%)$ \\
\hline Yes & $238(72.79 \%)$ \\
\hline Grand Total & $\mathbf{3 2 7}$ \\
\hline
\end{tabular}

238, i.e. $72 \%$ patients were pain free immediately after surgery.

9. Incidence of headache after surgery.

\begin{tabular}{|c|c|}
\hline & Headache after Surgery \\
\hline No & $246(75.22 \%)$ \\
\hline Yes & $81(24.78 \%)$ \\
\hline Grand Total & $\mathbf{3 2 7}$ \\
\hline
\end{tabular}

Only 81 i.e. $24.78 \%$ females had headache postoperatively, which may or may not have been postdural puncture headache.

10. Incidence of backache post-surgery.

\begin{tabular}{|c|c|}
\hline & Post-Surgery Backache \\
\hline No & $147(44.95 \%)$ \\
\hline Yes & $180(55.05 \%)$ \\
\hline Grand Total & $\mathbf{3 2 7}$ \\
\hline
\end{tabular}

180 out of 327 , i.e. almost 55\% patients had experienced backache after the surgery.

11. Backache and type of anaesthesia.

\begin{tabular}{|c|c|c|c|}
\hline Backache & No & Yes & Total \\
\hline General & $13(52 \%)$ & $12(48 \%)$ & 25 \\
\hline Spinal & $118(44.97 \%)$ & $146(55.03 \%)$ & 264 \\
\hline Epidural & $6(35.29 \%)$ & $11(64.71 \%)$ & 17 \\
\hline Cannot Recall & $10(47.61)$ & $11(52.39 \%)$ & 21 \\
\hline Total & $\mathbf{1 4 7}$ & $\mathbf{1 8 0}$ & $\mathbf{3 2 7}$ \\
\hline
\end{tabular}

The difference is insignificant $\mathrm{X}^{2}=0.037, \mathrm{p}=0.848$.

12. Incidence of persistent backache.

\begin{tabular}{|c|c|}
\hline & Backache Still Present \\
\hline No & $147(44.96 \%)$ \\
\hline Yes & $180(55.04 \%)$ \\
\hline Grand Total & $\mathbf{3 2 7}$ \\
\hline
\end{tabular}

The same number of patients, 180 i.e. 55\% have persistent backache even years after the surgery.

13. Whether patients attribute persistent backache to spinal anaesthesia.

\begin{tabular}{|c|c|}
\hline & SA Related \\
\hline NA & $147(44.95 \%)$ \\
\hline No & $66(20.18 \%)$ \\
\hline Yes & $114(34.87 \%)$ \\
\hline Grand Total & $\mathbf{3 2 7}$ \\
\hline
\end{tabular}

In our study out of the 180 patients who had persistent backache, 114 attributed the backache to the spinal anaesthesia they had received during their caesarean sections.

14. Whether patient would prefer receiving spinal anaesthesia in future.

\begin{tabular}{|c|c|}
\hline & Still Prefer SA \\
\hline No & $132(40.36 \%)$ \\
\hline Yes & $195(59.64 \%)$ \\
\hline Grand Total & $\mathbf{3 2 7}$ \\
\hline
\end{tabular}

Of the 327 patients, almost $60 \%$ patients felt they would opt for spinal anaesthesia if required in future.

15. Overall experience of caesarean section.

\begin{tabular}{|c|c|}
\hline & Overall Experience \\
\hline Satisfactory & $275(84.09 \%)$ \\
\hline Not Satisfactory & $52(15.91 \%)$ \\
\hline Grand Total & $\mathbf{3 2 7}$ \\
\hline
\end{tabular}

\section{DISCUSSION}

Spinal anaesthesia is performed by injecting small amounts of local anaesthetic agent into the Cerebrospinal Fluid (CSF). It is easy to perform and provides excellent operating conditions for caesarean section. Compared with general anaesthesia, spinal anaesthesia has lower rates of venous thromboembolism, cardiac events, the need for postoperative analgesia, sympathetic responses to surgical stimulation along with few other life-threatening complications. ${ }^{3}$

Patient's comfort and satisfaction during surgery, especially during an emotional turmoil filled phase like caesarean section is of utmost importance. Simple practices like talking to patient before being wheeled in for surgery and showing the face of baby immediately post-delivery can improve the psychological state of the patient.

We conducted a cross-sectional study via a questionnaire on an online social media platform in a group, which consisted exclusively of mothers in the city of Mumbai. To our surprise, of the one lakh members only 328 females participated in the study, in spite of caesarean surgery being a very common procedure performed and complaints like persistent backache are often attributed to the spinal anaesthesia received by the patients for the same-

\section{Introduction by Anaesthetist}

In our study, the anaesthetist was introduced to 207 patients. In a study conducted by T. Kumaravadivel Dharmalingam, Nor Azian Ahmad Zainuddin, wherein they conducted a Survey on Maternal Satisfaction in Receiving Spinal Anaesthesia for Caesarean Section. All the patients were satisfied with the complete explanations provided by the trained personnel regarding applicable anaesthesia methods. However, evaluation of the understanding of these explanations among the patients revealed that $2 \%$ failed to completely understand, because they were unable to concentrate on the explanations because of labour pain. This was observed in emergency cases, where patients were in active phase of labour. ${ }^{4}$ 


\section{Type of Anaesthesia}

Among 327 females in our study 25 had received general anaesthesia, 264 had received spinal anaesthesia and 17 had received epidural anaesthesia, while 21 could not recall the type of anaesthesia received for caesarean section. Neuraxial anaesthesia techniques have several advantages including a decreased risk of failed intubation and aspiration of gastric contents, avoidance of depressant agents and the ability of the mother to remain awake and enjoy the birthing experience. In addition, it has been suggested that blood loss is reduced under regional anaesthesia for caesarean delivery. ${ }^{1}$

In a study conducted by Martin TC, Bell P, Ogunbiyi $\mathrm{O}$, where they conducted comparison of general anaesthesia and spinal anaesthesia for caesarean section in Antigua and Barbuda. They concluded that GA and SA appear equally safe, but SA was associated with significantly better outcome for both mothers and babies. ${ }^{4}$

Another study conducted by Charles S Algert, Jennifer R Bowen titled regional block versus general anaesthesia for caesarean section and neonatal outcomes: a populationbased study has shown that there are significant risks to the neonates of both resuscitation requiring intubation and of a poor Apgar score at 5 minutes for a range of delivery indications. The greatest RR of both adverse outcomes occurred in the low-risk planned repeat CS deliveries under $\mathrm{GA}$, but the greatest excess in risk attributable to GA was for emergency deliveries for foetal distress, where the infant would already have been compromised to some extent. ${ }^{5}$

\section{Apprehension during Induction of Anaesthesia}

In our study, $52 \%$ did not feel apprehensive during induction of anaesthesia suggesting almost equal number of patients felt apprehensive during the same.

In a study conducted by IR Taylor and AS Bullough et al, which assessed partner anxiety prior to elective caesarean section under regional anaesthesia, they found that there is evidence that mothers experience anxiety and sometimes depression in the perioperative period, that the support of their partner is helpful in reducing their stress levels and that the majority talk to their partner or relative during this time for reassurance. 6

\section{Position during Spinal Anaesthesia Induction}

In our study almost $76 \%$ received spinal anaesthesia in sitting position, while the rest received in lateral position.

The sitting position was found to be significantly comfortable- $\mathrm{X}^{2}=18.996, \mathrm{p}=0.00001$ (highly significant). This result was surprising because in lateral general position is perceived to be more comfortable than the sitting position while receiving spinal anaesthesia. In a study conducted by Shahzad K and Afshan G titled - Induction position for spinal anaesthesia: sitting versus lateral position, they concluded that both sitting and lateral positions have similar effects on sensory and motor blockade and haemodynamic stability. However, patients generally found lateral position very comfortable. ${ }^{7}$ In our study, $70 \%$ patients were comfortable during induction of spinal anaesthesia.

\section{Baby shown Immediately after Birth}

238 patients were shown the baby immediately after birth. This question was not applicable to 25 patients who had received general anaesthesia. Showing baby to the mother immediately after birth or making a skin to skin contact between mother and the child is very essential for the wellbeing of both. In a study conducted by Raylene Phillips titled Uninterrupted Skin-to-Skin Contact Immediately after Birth, they concluded that hospital protocols can be modified to support uninterrupted skin-to-skin contact immediately after birth for both vaginal and caesarean births. This is a once-ina-lifetime experience and should not be interrupted unless the baby or mother is unstable and requires medical resuscitation. ${ }^{8}$

\section{Pain after Surgery}

One of the advantages of regional anaesthesia over general anaesthesia is that the patient is pain free immediately after surgery, till the level begins to recede and rescue analgesic is needed. In our study, 238 i.e. $72 \%$ patients were pain free immediately after surgery.

\section{Incidence of Headache}

In our study, $32.92 \%$ females had headache postoperatively. PDPH will develop in $50 \%$ or more of patients after accidental dural puncture with an epidural needle. However, not all postpartum headaches occur as a result of dural puncture.

A large analysis reported that headaches occurred in $15 \%$ of parturients who did not receive an epidural and in $12 \%$ of parturients who had an epidural but did not show evidence of dural puncture. ${ }^{9}$ Other causes of headache in the postpartum period include non-specific headache, migraine, hypertension, pneumocephalus, infection including sinusitis and meningitis, cortical vein thrombosis and intracerebral pathology. In addition, because coffee and tea intake is so prevalent in our society one should also consider caffeine withdrawal in the differential diagnosis. PDPH has the typical features of a postural headache that is worsened by standing or straining and relieved by lying down. ${ }^{1}$ In a study conducted by Rhee WJ et al, to determine the factors in patient dissatisfaction and refusal regarding spinal anaesthesia, they found that post-operative backache was associated with dissatisfaction and refusal of spinal blocks. ${ }^{10}$

\section{Incidence of Acute and Chronic Backache}

In our study, 180 out of 327, i.e. almost 55\% patients had experienced backache after the surgery. The same number of patients, 180 i.e. 55\% have persistent backache even years after the surgery. Out of these, 114 attributed the backache to the spinal anaesthesia they had received during their caesarean sections.

We compared incidence of backache against number of children and found that there was no statistically significant difference in backache in mothers bearing one or more children.

When we compared incidence of backache in patients receiving different types of anaesthesia, there was no statistically significant difference in the incidence of backache in those receiving spinal, general or epidural anaesthesia. This finding is very important in establishing the fact that backache after caesarean section has other aetiologies, which are common to all forms of anaesthesia and the physiological changes of pregnancy and postpartum period, and should not 
be attributed to the spinal anaesthesia received for caesarean section.

In their study, T. Kumaravadivel et al found that although the backache might not directly be attributed to the spinal block, it was difficult to distinguish the actual cause of backache. Other variables such as positioning during surgery, a tightly applied surgical dressing, surgical trauma, operation time, age, pregnancy, needle type and the number of punctures can also contribute to post-operative backache.

In their review article 'the causes, prevention and management of post spinal backache: an overview,' Mohammad Kashif Rafique et al concluded that it was the major cause for $13.4 \%$ patients refusing spinal anaesthesia. Multiple factors are involved in the pathogenesis of postoperative back pain and include type and duration of surgery, duration of immobilisation, and the position of the patient during spinal puncture. Diagnosis of back pain is not simple; contributing factors may include needle trauma, surgical positioning and injection of saline or local anaesthetic into the interspinous ligaments, development of a supraspinous haematoma, excessive stretching of ligaments after relaxation of paraspinal muscles and localised trauma to the intervertebral disc. Its relationship with various types and sizes of spinal needle is yet to be confirmed.

In a prospective study conducted by Alison Macarthur et al, to determine whether epidural anaesthesia during labour and delivery is a risk factor for postpartum back pain, they concluded that postpartum low back pain was common but decreased considerably over the short term. The association between epidural anaesthesia and postpartum low back pain was inconsistent overtime with a significantly increased risk of low back pain (Epidural vs. non-epidural) noted only on the first day after delivery. ${ }^{11}$

Nikolajsen et al conducted a questionnaire based study to evaluate chronic pain following caesarean section. Total of 220 patients $(90.2 \%)$ answered the questionnaire. The mean follow-up time was 10.2 months (Range 6 - 17.6). Postoperative pain resolved in most patients within 3 months, but 27 patients $(12.3 \%)$ still had pain at the time of the interview. They concluded that chronic pain after caesarean section seems to be a significant problem in at least $5.9 \%$ of patients. 12

\section{Willingness for taking Spinal Anaesthesia in Future}

Of the 327 patients in our study, almost $60 \%$ patients felt they would opt for spinal anaesthesia if required in future. In their study, 'Survey on Maternal Satisfaction in Receiving Spinal Anaesthesia for Caesarean Section,' T Kumaravadivel et al concluded that side effects, inadvertent mistakes and unskilful techniques can negatively affect patient perspectives about spinal anaesthesia. Some factors which can increase the satisfaction rate of patients who are undergoing a surgery with spinal anaesthesia are as follows: First, a patient's opinion is very important when deciding the anaesthetic method. Second, the anaesthetists must provide complete explanations regarding spinal anaesthesia before surgery. Third, the anaesthetists should have good rapport with their patients. Finally, the anaesthetist should manipulate the patient skilfully and sedate the patients if they wish. ${ }^{4}$

\section{Overall Satisfaction}

In spite of all the apprehensions and prejudices, in our study 84.09\% women found the overall experience of anaesthesia for caesarean surgery satisfactory. This could be the result of use of smaller bore needles for spinal anaesthesia, thus resulting in a reduced incidence of postdural puncture headache and improvement in drugs used for sedation or general anaesthesia.

\section{CONCLUSION}

In conclusion, this study shows that in spite of the advantages of neuraxial blockade for caesarean surgery, a number of factors can decide the comfort of a patient during the surgery, including whether anaesthetist spoke to the patient prior to surgery, the apprehension felt while receiving anaesthesia, the position in which it was given, whether baby was shown immediately after birth etc.

Secondly, backache is very common in these patients, but most of the times it becomes persistent due to factors like physiological changes of pregnancy and postpartum period. Irrespective of its aetiology and pathogenesis, the postpartum backache is attributed to spinal anaesthesia or epidural anaesthesia received during caesarean surgery. Our study shows no statistically significant difference in the incidence of backache in mothers who have received spinal anaesthesia and those who have received general anaesthesia. Thus, backache is multifactorial and should not be attributed to the spinal anaesthesia received for caesarean section.

However, in spite of all the apprehensions and prejudices associated with it, $60 \%$ women were ready to receive spinal anaesthesia in the future and $84.09 \%$ found the overall experience satisfactory.

\section{REFERENCES}

[1] Hawkins JL, Koonin LM, Palmer SK, et al. Anesthesiarelated deaths during obstetric delivery in the United States, 1979-1990. Anesthesiology 1997;86(2):27784.

[2] Corso M, Grondin D, Weis CA. Postpartum low back pain: it is not always What You Think. Obstet Gynecol Cases Rev 2016;3(3)1-5.

[3] Dharmalingam TK, Zainuddin NAA. Survey on Maternal Satisfaction in Receiving Spinal Anaesthesia for Caesarean Section. Malays J Med Sci 2013;20(3):51-4.

[4] Martin TC, Bell P, Ogunbiyi O. Comparison of general anaesthesia and spinal anaesthesia for caesarean section in Antigua and Barbuda. West Indian Med J 2007;56(4):330-3.

[5] Algert CS, Bowen JR, Giles WB, et al. Regional block versus general anaesthesia for caesarean section and neonatal outcomes: a population-based study. BMC Med 2009; 7:20.

[6] Taylor IR, Bullough AS, Van Hamel JCM, et al. Partner anxiety prior to elective Caesarean section under regional anaesthesia. Anaesthesia 2002;57(6):584605.

[7] Shahzad K, Afshan G. Induction position for spinal anaesthesia: sitting versus lateral position. J Pak Med Assoc 2013;63(1):11-5.

[8] Phillips R. Uninterrupted skin-to-skin contact immediately after birth. NAINR 2013;13(2):67-72. 
[9] Benhamou D, Hamza J, Ducot B. Postpartum headache after epidural analgesia without dural puncture. Int J Obstet Anesth 1995;4(1):17-20.

[10] Rhee WJ, Chung CJ, Lim YH, et al. Factors in patient dissatisfaction and refusal regarding spinal anesthesia. Korean J Anesthesiol 2010;59(4):260-4.
[11] Macarthur A, Macarthur C, Weeks S. Epidural anaesthesia and low back pain after delivery: a prospective cohort study. BMJ 1995;311(7016):13369.

[12] Nikolajsen L, Sørensen HC, Jensen TS, et al. Chronic pain following Caesarean section. Acta Anaesthesiologica Scandinavica 2004;48(1):111-6. 